\title{
Landscape Planning and Conservation Biology: Systems Thinking Revisited
}

\author{
JOAN IVERSON NASSAUER \\ "What survives is the organism-in-its-environment." Fritjof Capra. \\ 1982. The Turning Point: Science, Society, and Rising Culture.
}

University of Michigan, School of Natural Resources and Environment, Ann Arbor, MI 48109-1041, U.S.A., email nassauer@umich.edu

other. A key to this productive exchange may be for each to reclaim and refine a systems approach to defining ques-
Both conservation biology and landscape planning are fields enriched by their solid grounding in professional practice and the real world. Practicing conservation biologists know that landscape planning processes affect biodiversity on the ground, and practicing landscape planners know that biodiversity issues can decisively influence acceptance of planned change. Such pragmatic recognition, however, is not enough to advance the fields. Enormous ecological and public benefits could accrue if the two fields were to actively inform and change each other.

Their similar aspirations to affect landscape change are shared with very few disciplines, and that should be a powerful incentive for collaboration, but their roots and cultural imperatives are sufficiently different to distract them from each other. Whereas conservation biology starts with inquiry into the relationships between species and habitats, landscape planning starts with questions about human occupancy of places and regions. While conservation biology depends on the cultures of basic and applied sciences, landscape planning depends on the cultures of professions: design, planning, real estate, and law. Whereas conservation biology is accountable to habitat as an outcome, landscape planning is accountable to human quality of life as an outcome. That habitats and quality of life rest on the same substrate of ecological quality is rather obvious to those who begin planning for places by inquiring into their ecological foundations. Even in this time of burgeoning approaches to sustainable design, however, the systemic, multiscale character of ecological functions clashes with the more piecemeal character of professional, political, and market mechanisms for landscape change.

Conservation biology and landscape planning could be engaged in a dynamic exchange beyond these differences, in which each refines the definition and effect of the tions and implementation strategies. In both fields, questions that pay attention to intrinsic connections between habitats and the extensive matrix of human-dominated land uses suggests unexplored problems and potentials for landscape change. Looking back at the beginnings of conservation biology and the earlier renaissance of landscape planning in the era of the first Earth Day, one sees strong evidence of systems thinking in both fields. So the challenge is not to adopt systems approaches, but to redirect systems approaches to seek landscape planning synergies between conservation biology and landscape planning.

Ecological planning approaches that were articulated in the 1960s renaissance by Carl Steinitz, Ian McHarg, and Phil Lewis exemplify multiscalar systems thinking. These approaches integrated biogeophysical and human factors to analyze and re-envision regions as functioning ecological and cultural systems. They were widely adopted to develop plans for wildlife refuges, national parks, national and state forests, metropolitan regions, counties, and entire states. In succeeding decades, the geographic information system technology and data for using these approaches have become commonplace, but the cultural and political mindset for acting on their implications has dwindled. The very political and property boundaries that were subordinated to more extensive ecological scales in these early plans frequently quashed their implementation. At least in the United States, the contemporary zeitgeist has warmed to local and private approaches to landscape planning, including protection of biodiversity.

Perhaps as a consequence, both fields recently have exhibited a propensity for framing relationships between landscape and biodiversity within more narrow conceptual, temporal, and spatial bounds. Focusing biodiversity concerns on lands explicitly set aside as habitat, whether 
as a reserve or as an ecosystem type (e.g., wetland or lake), exemplifies this more narrow perspective. While the benefits of protecting such habitats are indisputable, the potential for other, human-dominated land uses also to enhance biodiversity has been largely overlooked in landscape planning. At the same time, the possibility that a future landscape matrix could surround protected areas with improved ecological function has received little attention in conservation biology. A systems approach suggests creatively examining other land uses, near and far from reserves, as well as other plausible landscape matrix futures. This approach draws on both conservation biology and landscape planning (as well as a panoply of fields including landscape ecology, hydrology, and economics) to frame questions both broadly and plausibly.

Conservation biology and landscape planning must be pragmatic about the public and political mood to accomplish landscape change. But that pragmatism should not cause anyone to lose sight of the regional and global scales of critical ecological functions. Rather it might be cause for both fields to search for characteristics of land use, landscape, and biological systems that invite the fields to evolve together in complementary ways. Toward this goal, some important questions for both of these fields include the following:

(1) How do we measure and manage for biodiversity goals beyond reserves and their adjacent lands? (2) What biodiversity benefits can be achieved within different human-dominated land uses, including brownfields, subdivisions, transportation infrastructure, stormwater infrastructure, and agriculture? (3) How do we manage for biodiversity goals within recognized habitat types like remnant ecosystems, wetlands, lakes, and streams that oc- cur within properties that have other, human-dominated land uses? (4) How do we formulate biodiversity goals for relatively small, individual parcels of land when we know that their aggregated effect at more extensive scales is very important? (5) How do we account for the biodiversity effects of cultural habits, economic and popular preferences, and political and planning conventions? (6) How and in what cases can we use culture to enhance biodiversity? (7) What biodiversity benefits can we imagine, document, and propose for land use changes motivated by other societal goals (e.g., flood control)? (8) In a time of declining support for public sector goods, how do we sustainably address the dilemma of public ownership of land for biodiversity benefits? and (9) What are effective tools for maintaining and creating biodiversity on both public and private lands?

Landscape planning and conservation biology need to be engaged together to find the systemic relationships that address these questions. This engagement should take the form of experiments, investigations, and demonstrations in practice and research. Good examples of this sort of engagement have been conducted in the developing world. Inspiring challenges for the two fields also have grown out of active ecological restoration across the entire spectrum of land uses in Australia and New Zealand. Other important work is emerging in urban ecological design, planning, and research in America and multifunctional planning and research in Europe. The critical systems links may vary with culture, politics, and economies. In all settings, conservation biologists and landscape planners need to maintain an eye for the possibility of and an inclination for the messy work of exploring links in human and biogeochemical systems.

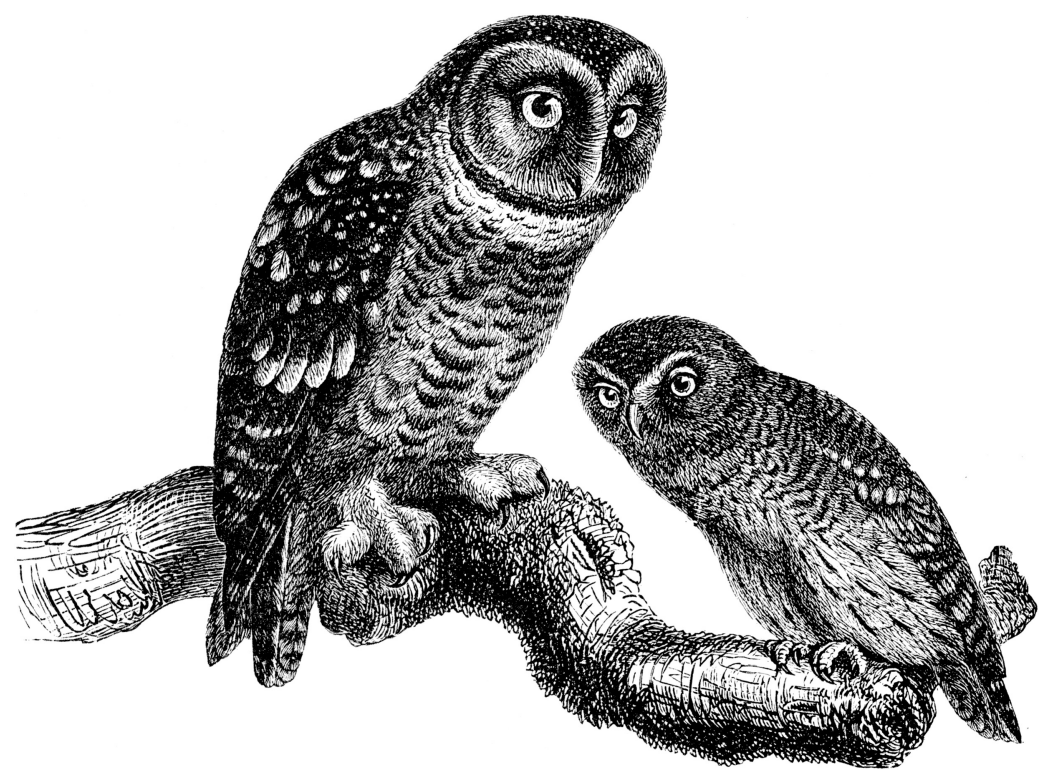

